\title{
Tree-ring-based annual precipitation reconstruction in Kalaqin, Inner Mongolia for the last 238 years
}

\author{
LIU Yu ${ }^{1,2^{*}}$, WANG CaiYong ${ }^{2}$, HAO WenJun ${ }^{3}$, SONG HuiMing ${ }^{1,4}$, CAI QiuFang ${ }^{1}$, TIAN Hua ${ }^{1}$, \\ SUN Bo ${ }^{1,4} \&$ Hans W. LINDERHOLM ${ }^{5}$ \\ ${ }^{1}$ State Key Laboratory of Loess and Quaternary Geology, Institute of Earth Environment, Chinese Academy of Sciences, Xi'an 710075, China; \\ ${ }^{2}$ Department of Environment Science and Technology, School of Human Settlements and Civil Engineering, Xi'an Jiaotong University, Xi'an \\ 710049, China; \\ ${ }^{3}$ Climate Research Center of Inner Mongolia, Hohhot 010051, China; \\ ${ }^{4}$ Graduate University of Chinese Academy of Sciences, Beijing 100049, China; \\ ${ }^{5}$ Regional Climate Group, Department of Earth Sciences, University of Gothenburg, 40530 Gothenburg, Sweden
}

Received March 8, 2011; accepted July 14, 2011

\begin{abstract}
A tree-ring-width chronology of Pinus tabulaeformis from Kalaqin, Inner Mongolia was developed using modern dendrochronological techniques. Based on the results of correlation function analysis, the total precipitation from the previous August to current July was reconstructed for 1771-2008 AD with an explained variance of 49.3\%. The reconstruction correlated well with the dryness/wetness series derived from historical documents, as well as the precipitation reconstruction of the Chifeng-Weichang region. There were eight intervals with greater precipitation than the average (associated with the strong East Asian summer monsoon) and seven intervals lower than the average (weak monsoon). A power spectrum analysis showed that there were $120 \mathrm{a}, 80 \mathrm{a}, 8 \mathrm{a}$ and 2 a periodicities.
\end{abstract}

Kalaqin, Inner Mongolia, Pinus tabulaeformis, tree-ring width, precipitation, reconstruction

Citation: Liu Y, Wang C Y, Hao W J, et al. Tree-ring-based annual precipitation reconstruction in Kalaqin, Inner Mongolia for the last 238 years. Chinese Sci Bull, 2011, 56: 2995-3002, doi: 10.1007/s11434-011-4706-6

As an important proxy to study paleoclimates, tree rings are widely used to reconstruct past climate, such as temperature $[1,2]$, precipitation [3,4] and drought index [5] back to hundreds of years. In recent years, great progress in dendroclimatological research has been made in China, and a large amount of valuable data has been collected. Temperatures for the last 2500 years [6-10] and precipitation for the last 2300 years [11-13] have been reconstructed for the Tibetan Plateau. Runoff series for several watersheds were also reconstructed using tree rings [14,15]. These achievements helped researchers to understand the past climatic variations in China in the context of global climate change. For the north margin of the East Asian summer monsoon [16], high-resolution tree-ring records were used to reconstruct

*Corresponding author (email: liuyu@ @loess.llqg.ac.cn) temperature [17] and precipitation [18-22] variations over the past few hundred years. The first tree-ring based precipitation prediction was also carried out [23], which has been proved to be largely consistent with real precipitation records until now.

Compared with the vast territory in northern China, treering study sites are still sparse. To better understand the past climate variation patterns over large spatial scales, a treering network should be established in northern China.

In this study, we present a tree-ring based annual precipitation (previous August to current July) reconstruction for the Kalaqin region of Inner Mongolia from 1771 to 2008 AD. The rainfall series were compared with historical documents and other precipitation reconstructions nearby to investigate the temporal and spatial characteristics of climatic variations. 


\section{Methods and materials}

\subsection{Sampling and chronology development}

Kalaqin is located on the north slope of the Qilaotu Mountains in eastern Inner Mongolia. The area has diverse physiographical conditions with elevations from $500 \mathrm{~m}$ in the west to $1890 \mathrm{~m}$ in the east. It is also a transition region between agricultural and prairie land with a temperate continental monsoon climate. The climate of Kalaqin is typically windy and dry in the spring, with greater than average rainfall and temperature in the summer, early frost in the autumn and a cold winter with little snow. The annual mean temperature ranges between 3.5 and $7^{\circ} \mathrm{C}$, and the annual mean precipitation is around $421 \mathrm{~mm}$, mainly concentrated in July and August [24].

The sampling site $\left(41^{\circ} 52^{\prime} 11^{\prime \prime} \mathrm{N}, 118^{\circ} 47^{\prime} 27^{\prime \prime} \mathrm{E}\right.$, elevation 1108-1198 m, Figure 1) is located in Ma'anshan National Forest Park, where Larix principis-rupprechtii Mayr and Pinus tabulaeformis Carr. are the major conifer species. Trees grow on thin yellow brown soil $(10-50 \mathrm{~cm})$, separated by $20-50 \mathrm{~m}$; thus, the canopy is discontinuous. According to the International Tree-Ring Data Bank standard, we collected two cores per tree from 29 Pinus tabulaeformis, and this group of samples was named as KLQ (Figure 1).

In the laboratory, samples were dried, mounted and surfaced [25] following standard dendrochronological procedures. After cross-dating, ring widths were measured to a precision of $0.01 \mathrm{~mm}$ using LINTAB.

Cross-dating quality control was performed with the COFECHA program [26]. The results showed that the mean correlation coefficient of each series with a master series was 0.81 , the mean sensitivity was 0.51 , and the first-order autocorrelation coefficient was 0.53 . Statistical analysis revealed that trees were strongly influenced by common

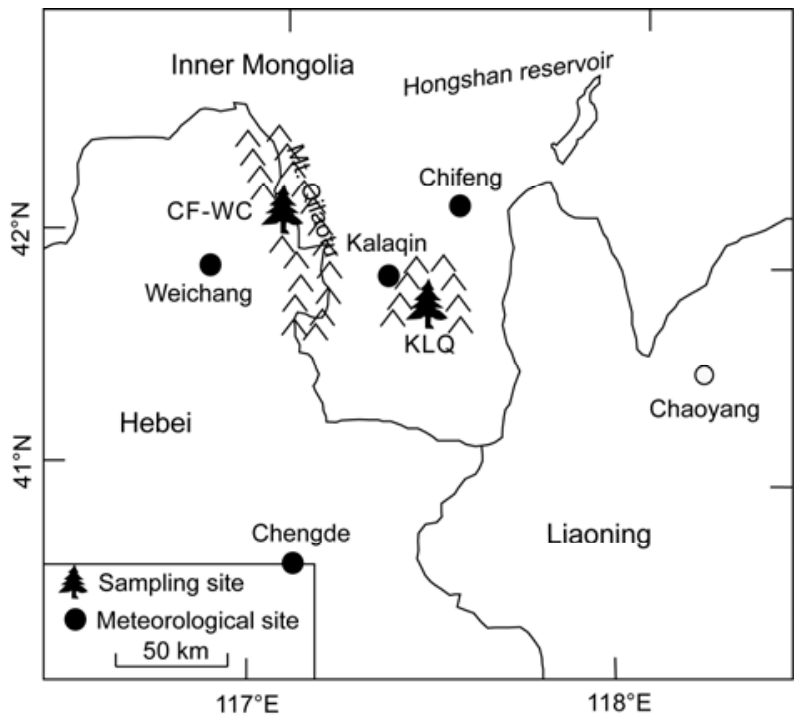

Figure 1 Location of sampling sites and meteorological stations in the Kalaqin region. climatic factors. Absent rings were found in 1861, 1906, 1961, 1972, 1986 and 2000. The rate of absent rings was $0.85 \%$, which is much less than $4.4 \%$ found for ChifengWeichang (Figure 1) [20], in the west of the Kalaqin region, indicating that Chifeng-Weichang is much drier.

The chronology was developed using the ARSTAN program [27] after excluding seven cores, which were less matched with others. A total of 51 cores from 26 trees were used to develop the chronology. To retain as much lowfrequency signals as possible, negative exponential curves or linear regression curves were applied to fit growth trends. By the minimum Akaike Information Criterion, the best regression model was determined following order selection. Then, the ring-width measurement series were transformed into an index series and combined into a single one using a biweighted robust mean [27].

Thus, three kinds of chronologies were obtained: standardized (STD), residual (RES) and the autoregressive standardized (ARS). In this paper, STD chronology was used for further analysis because it preserves both low and high frequency signals. Subsample signal strength (SSS) [28] was used to assess the adequacy of replication for the early years of the chronologies. We restricted our analysis to the period with an SSS of at least 0.80; this threshold corresponded to a minimum sample depth of three trees starting from 1771. The statistical features of the STD chronology are shown in Table 1.

\subsection{Ring width-climate response}

There are four meteorological stations around the sampling site, Chengde $\left(40^{\circ} 35^{\prime} 24^{\prime \prime} \mathrm{N}, 117^{\circ} 34^{\prime} 12^{\prime \prime} \mathrm{E}, 386 \mathrm{~m}\right)$, Chifeng $\left(44^{\circ} 9^{\prime} 36^{\prime \prime} \mathrm{N}, 118^{\circ} 33^{\prime} 36^{\prime \prime} \mathrm{E}, 568 \mathrm{~m}\right)$, Kalaqin Banner (41 $55^{\prime}-$ $\left.36^{\prime \prime} \mathrm{N}, 118^{\circ} 42^{\prime} 5^{\prime \prime} \mathrm{E}, 737 \mathrm{~m}\right)$ and Weichang $\left(41^{\circ} 55^{\prime} 48^{\prime \prime} \mathrm{N}\right.$, $\left.117^{\circ} 45^{\prime} 0^{\prime \prime} \mathrm{E}, 843 \mathrm{~m}\right)$.

The monthly mean precipitations and temperatures of each station were calculated and shown in Figure 2. Rainfall from June to August made the greatest contribution to the

Table 1 Statistics features of Kalaqin chronology

\begin{tabular}{lc}
\hline \multicolumn{1}{c}{ Statistics } & STD \\
\hline Mean sensitivity & 0.42 \\
Standard deviation & 0.41 \\
Kurtosis & 0.09 \\
Skewness & 0.59 \\
First-order autocorrelation & 0.28 \\
Mean correlation among all series & 0.59 \\
Mean correlation among trees & 0.58 \\
Mean correlation within a tree & 0.64 \\
Variance in first PC (\%) & 60.4 \\
Agreement with population chronology & 0.89 \\
First year SSS $>0.80$ & 1771 (three trees) \\
\hline
\end{tabular}



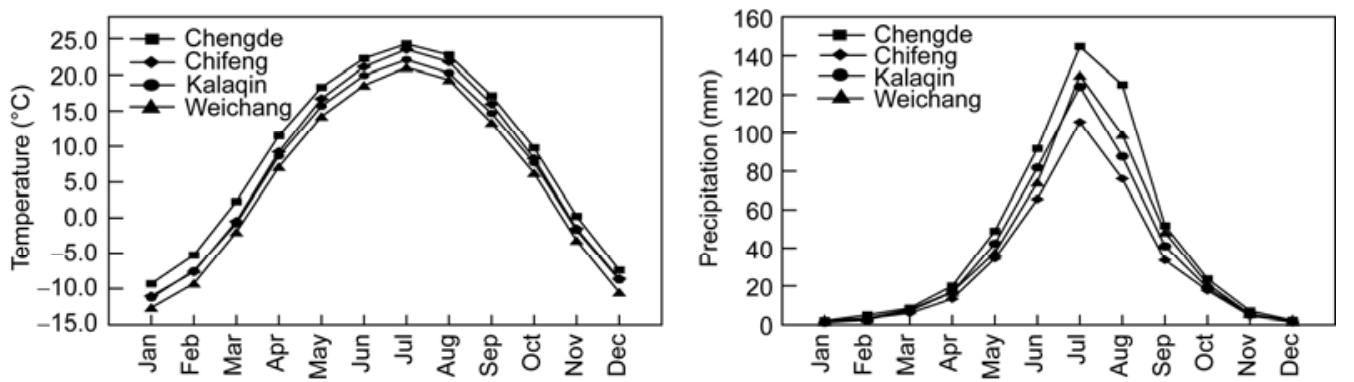

Figure 2 Monthly mean temperature and sum of precipitation at four meteorological stations (1959-2008).

annual total, and the highest rainfall occurred in July. The observed data were tested for homogeneity and randomness, and the results showed that temperature and precipitation data of the four meteorological stations were qualified for further analysis [29,30].

Correlation function analysis was used to explore the relationship between tree-ring width and climate during the observation period. During the calculation process, data from Kalaqin meteorological station (1959-2008) were used because it is the nearest to the sampling site, about $5 \mathrm{~km}$ away. Figure 3 showed that no significant relationship was found between ring width and monthly mean temperature except for June, and the mean temperature from May to July $\left(T_{57}\right)(r=-0.52)$. However, the ring width was significantly correlated with precipitation, especially with the total rainfall from previous August to current July $\left(P_{87}\right)$ when combining the months $(r=0.67)$, which was similar to that of the Chifeng-Weichang region [25]. Partial correlation analysis showed that ring width was significantly correlated with $P_{87}$ when $T_{57}$ was fixed $\left(r_{\text {partial }}=0.52\right)$, but no significant correlation was found between ring width and $T_{57}$ when $P_{87}$ was fixed $\left(r_{\text {partial }}=-0.24\right)$. This meant that in the study region tree ring growth was mainly limited by precipitation, and not temperature.

Generally speaking, annual precipitation and seasonal

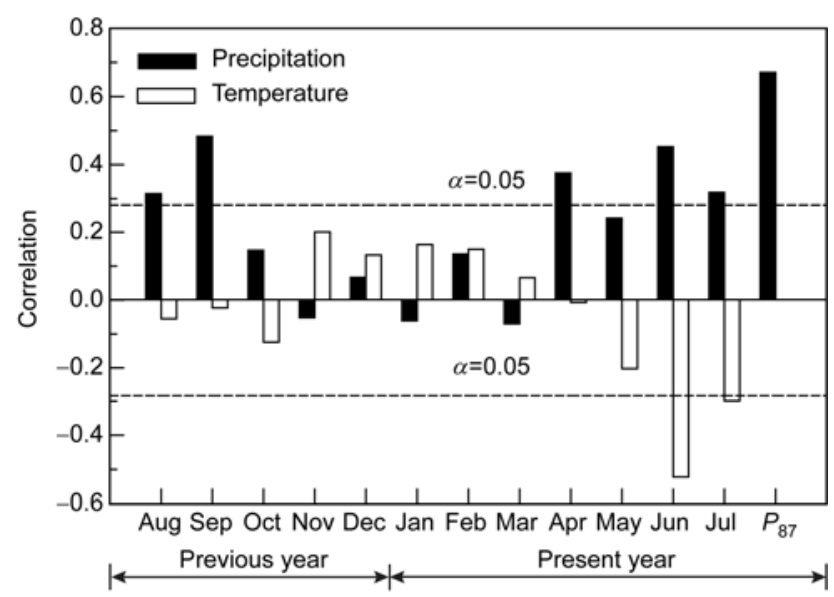

Figure 3 Correlations between ring width and the meteorological data from the Kalaqin Station (1959-2008). $P_{87}$, Total precipitation from prior August to current July. patterns of precipitation affect tree growth in arid to semiarid regions. The results of the correlation function (Figure 3) analysis suggested that abundant rainfall and suitable climatic conditions in a previous year could benefit nutrition storage for the following growing season. Sufficient precipitation of current year could also lead to the production of wide rings. However, a lack of rainfall during the previous August to October, as well as current April to July would restrict tree growth, and form narrow rings.

\subsection{Transfer function}

Based on the correlation analysis above, a transfer function was developed to reconstruct the $P_{87}$ as

$$
P_{87}=192.72 W_{\mathrm{t}}+252.79
$$

$\left(N=49, r=0.67, R^{2}=44.9 \%, R_{\text {adj }}^{2}=43.7 \%, F=38.33, P<\right.$ $0.0001)$,

where $P_{87}$ is the total precipitation from the previous August to current July, $W_{\mathrm{t}}$ is the ring-width index at the $t$ year.

During the calibration period 1960-2008, the reconstructed series tracked the observational data (Figure 4). $P_{87}$ was highly correlated with total precipitation of current year (from January to December) with $r=0.75(P<0.0001)$, so $P_{87}$ could reflect annual precipitation in our study area. Rainfall during the rainy season accounted for $68.3 \%$ of the annual amount [16], indicating that precipitation in the study area was mainly brought by the East Asian summer monsoon.

In Table $2, S_{1}$ is the general sign test between the observations and the reconstruction that measures the associations at all frequencies. $S_{2}$, which reflects the high-frequency climatic variations, is a similar test to above, and it is made for the first differences; $t$, product mean and RE, reduction of error.

The verification results (Table 2) showed that the sign test of both $S_{1}$ and $S_{2}$ exceeded the $95 \%$ confidence level, which meant that variations of the observed and reconstructed series were similar at all frequencies. The product mean $(t)$ was 5.66, which exceeded 3.50 (the $99 \%$ confidence level). The reduction of error (RE) was 0.45 . All these statistical items demonstrated that the transfer function was valid and reliable. 


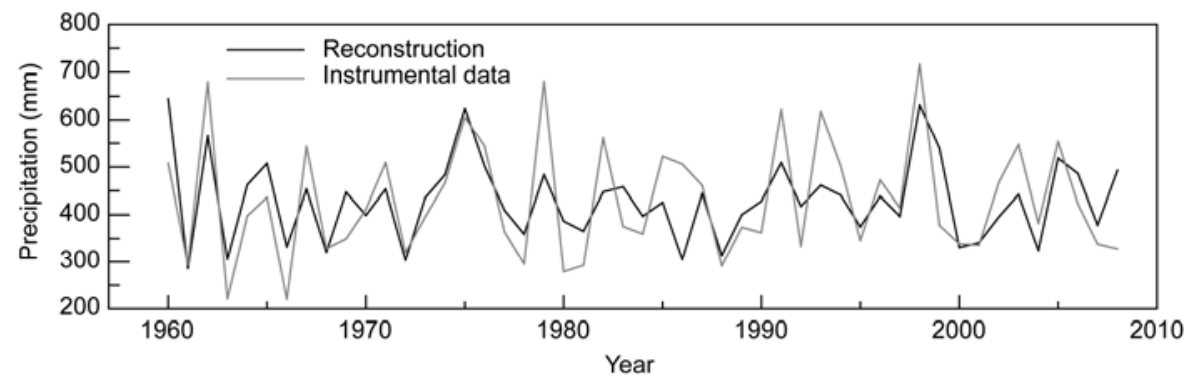

Figure $4 P_{87}$ comparison between estimation based on tree rings and observation from the Kalaqin Station (1960-2008).

Table 2 Verification result of the $P_{87}$ reconstruction

\begin{tabular}{cccccccc}
\hline & Period & $r$ & $F$ & $\mathrm{~S}_{1}$ & $\mathrm{~S}_{2}$ & $t$ & $\mathrm{RE}$ \\
\hline$P_{87}$ & $1960-2008$ & 0.67 & 38.33 & $32\left(32,{ }^{*} 34^{* *}\right)$ & $41\left(32,{ }^{*} 34^{* *}\right)$ & 5.66 & 0.45 \\
\hline$* 95 \%$ confidence level; ** 99\% confidence level. & & & & &
\end{tabular}

* 95\% confidence level; ** 99\% confidence level.

Further verifications were conducted using Bootstrap and Jack-knife statistical methods [31,32] to verify the stability and the reliability of the regression model [1]. Bootstrap resamples the data with replacement, maintaining the size of the sample equal to that of the original data set. Then, by repeating the computation of the statistic of interest many times, a more precise estimate of the Bootstrap distribution of the statistic is obtained. In this study, 100 iterations were carried out during the bootstrap process.

The basic idea behind Jack-knife is similar to that of the leave-one-out test, calculating the correlation of the time series after removing the values for one year progressively through the whole time period. The result of the Jack-knife suggested 1986 was an unusual year. For $P_{87}$, the observed value $(506 \mathrm{~mm})$ was much higher than the estimated $(304 \mathrm{~mm})$. Comparing this with the observation, the actual precipitation of May in 1986 was only $8.5 \mathrm{~mm}$ and June was $68 \mathrm{~mm}$, which were $80 \%$ and $17 \%$ lower than the average of other years at the same time, respectively. Moreover, the mean temperature of May and June reached $16.2^{\circ} \mathrm{C}$ and $21^{\circ} \mathrm{C}$, higher than the average values of other years. Insufficient rainfall in May and June limited tree growth, while high temperatures would increase evaporation and respiration; all these factors lead to the development of narrow ring in 1986. Although precipitation increased from July to September, it was too late to form a wide ring.

If 1986 was removed from the model [1], the correlation coefficient rises to $0.71\left(R^{2}=50.6 \%, R_{\text {adj }}^{2}=49.6 \%, F=47.21\right.$, $P<0.0001)$. However, 1986 was kept in the model as we could not be certain if other previous years were similar to this year.

The results of the Bootstrap and Jack-knife methods are shown in Table 3, among for which the Durbin-Watson (D/W) statistics were 2.08 and 2.12 respectively $(1.40<$ $\mathrm{D} / \mathrm{W}<2.60$ indicating there is no first-order autocorrelation in the residuals). In general, the results of the Bootstrap and Jack-knife methods were close to those that had been found
Table 3 Verification results of Bootstrap and Jack-knife methods for $P_{87}$ of Kalaqin

\begin{tabular}{lcll}
\hline \multirow{2}{*}{ Statistics } & $\begin{array}{c}\text { Calibration } \\
(1960-2008)\end{array}$ & \multicolumn{2}{c}{ Verification (1960-2008) } \\
\cline { 3 - 4 } & $\begin{array}{c}\text { Bootstrap (100 iterations) } \\
\text { Mean (range) }\end{array}$ & $\begin{array}{c}\text { Jack-knife } \\
\text { Mean (range) }\end{array}$ \\
\hline$R$ & 0.67 & $0.67(0.43-0.83)$ & $0.67(0.62-0.71)$ \\
$R^{2}$ & $44.9 \%$ & $45 \%(24 \%-72 \%)$ & $45 \%(39 \%-51 \%)$ \\
$R_{\text {adj }}^{2}$ & $43.7 \%$ & $44 \%(23 \%-71 \%)$ & $44 \%(37 \%-50 \%)$ \\
$\mathrm{SE}$ & 91.44 & $89.56(70.75-109.00)$ & $91.43(86.68-92.43)$ \\
$T$ & 8.03 & $8.00(4.98-10.58)$ & $7.96(7.50-8.47)$ \\
$F$ & 38.33 & $42.76(15.21-119.49)$ & $37.63(28.74-47.21)$ \\
$P$ & 0.0001 & 0.0001 & 0.0001 \\
$\mathrm{D} / \mathrm{W}$ & 2.12 & $2.06(1.65-2.41)$ & $2.12(1.90-2.27)$ \\
\hline & & &
\end{tabular}

in the full data set, which demonstrated the calibration function was stable and reliable.

We also used observation records obtained from three other meteorological stations near Kalaqin Banner to verify our results (Table 4). Correlation analysis showed that the reconstruction was significantly correlated with the observed records (Figure 5, Table 4) and the climatic variations of the four places were similar. This comparison indicates that our reconstruction is reliable and, at larger spatial scale, the precipitation variations are synchronous.

\section{Results and discussion}

\subsection{Precipitation reconstruction from 1771 to 2008 AD}

Based on the transfer function [1], we reconstructed the total precipitation from previous August to current July for the Kalaqin region from 1771 to 2008 AD (Figure 6). The mean precipitation of the reconstructed series was $440 \mathrm{~mm}$ and its standard deviation $(\sigma)$ was $79 \mathrm{~mm}$. Several fluctuations of dry/wet periods emerged in the precipitation curve. 
Table 4 Correlation analysis within Kalaqin, Chifeng, Weichang, Chengde and the $P_{87}$ reconstruction

\begin{tabular}{lcccc}
\hline & Kalaqin 1960-2008 & Chifeng 1952-2008 & Weichang 1952-2008 & Chengde 1952-2008 \\
\hline Kalaqin & 1.00 & & & \\
Chifeng & 0.78 & 1.00 & 1.00 & \\
Weichang & 0.64 & 0.74 & 0.70 & 1.00 \\
Chengde & 0.53 & 0.60 & 0.61 & 0.47 \\
Reconstructed $P_{87}$ & 0.67 & 0.57 & 1.00 \\
\hline$r, P<0.0001$ & & &
\end{tabular}

$r, P<0.0001$.

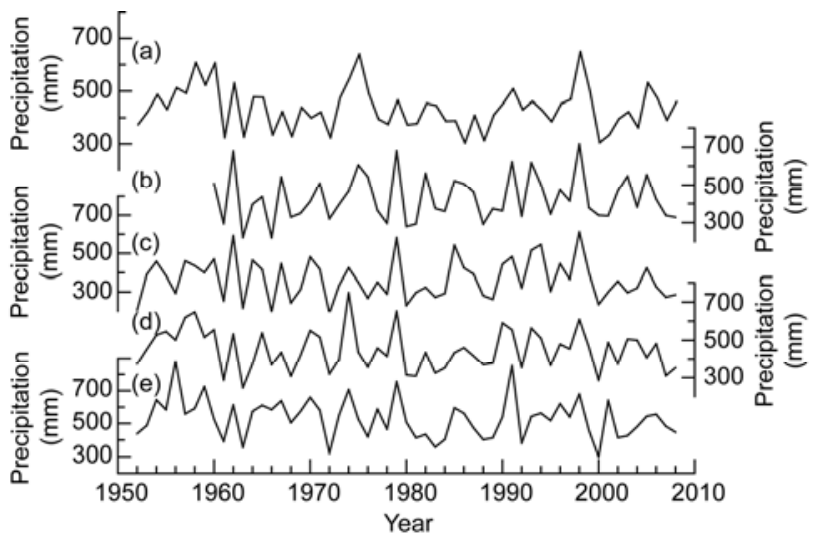

Figure 5 Comparisons of total precipitation from previous August to current July. (a) Reconstruction; (b) Kalaqin; (c) Chifeng; (d) Weichang; (e) Chengde.

In this study a wet year was defined as $>$ mean $+1 \sigma(=519$ $\mathrm{mm})$, and a dry year as $<$ mean $-1 \sigma(=361 \mathrm{~mm})$. During the past 238 years, there were 37 wet years and 41 dry years, which accounted for $15.5 \%$ and $16.8 \%$ of the whole reconstructed series respectively. The severe drought event recorded in the historical documents during 1784-1786 [33] was also captured by our tree-ring reconstruction. This was the driest period in the last 238 years in the Kalaqin region with a mean rainfall of $319 \mathrm{~mm}$, which was $27 \%$ lower than the average during the 238 years. A severe drought event over north and northwest China occurred in 2000 was also recorded by the reconstruction. As reported [34], six rivers and 34 reservoirs dried up around Chifeng city in that year, and the total precipitation was extremely low. The observed level of total precipitation was $331 \mathrm{~mm}$ and that of the reconstructed series was $305 \mathrm{~mm}$ in Kalaqin in 2000, which were $23 \%$ and $31 \%$ lower than $440 \mathrm{~mm}$, the average of previous years, respectively.

In 1998, most of China (including northeast China) suffered from flooding because of the incessant rainfall; this event was also captured by our reconstruction (Figures 4-6). In the reconstruction, the rainfall was $649 \mathrm{~mm}$, which was $48 \%$ more than the average, indicating that the Kalaqin region was also affected by flooding in 1998.

After smoothed by an 11-year moving average, the entire precipitation curve showed that there were eight wet periods with precipitation higher than the average $(>440 \mathrm{~mm})$ (Figure 6): 1774-1779, 1813-1855, 1892-1900, 1901-1912, 1913-1922, 1933-1963, 1972-1979 and 1993-1996. Among them, two intervals, 1813-1855 and 1933-1963, lasted for a long time period. There were seven dry periods with precipitation below the average (<440 mm): 1780-1812, 1856-1891, 1901-1912, 1923-1932, 1964-1971, 1980-1992 and 1997-2000. The period 1794-1812 was the driest, and

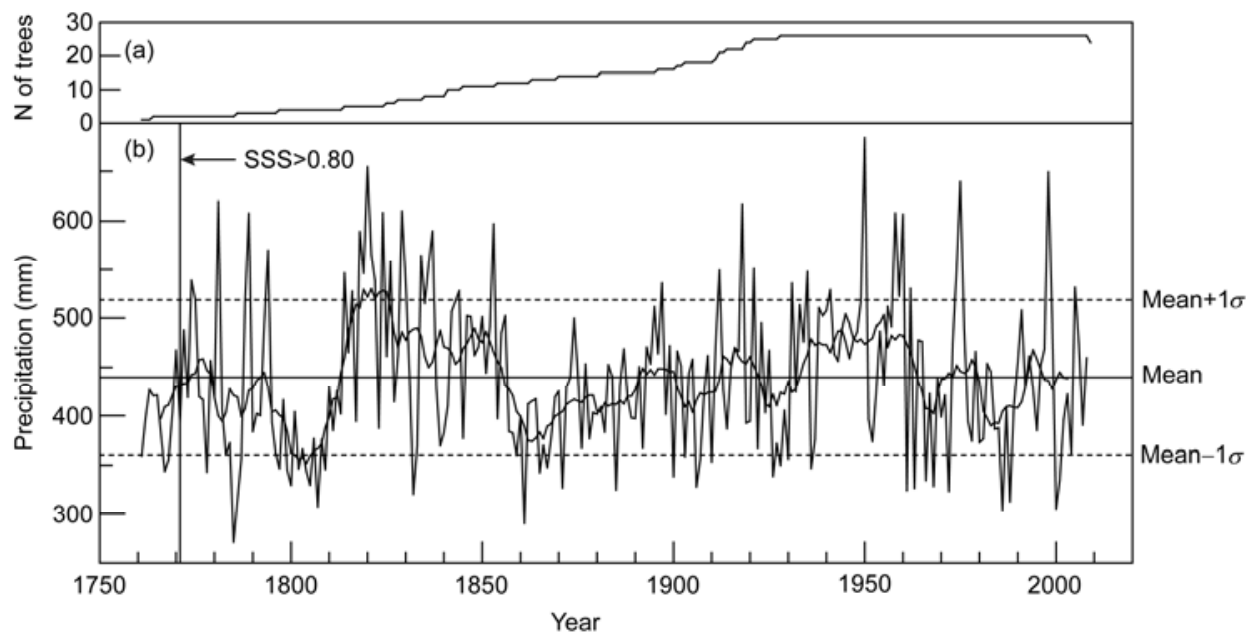

Figure 6 The precipitation reconstruction for Kalaqin region during 1771-2008. The smoothed line in (b) is the 11-year moving average; the horizontal line is the mean value of 1771-2008 AD. 
the period 1856-1891 was the longest. Since the 1960s, precipitation in this area has continuously increased $[35,36]$, even though the precipitation is still in the normal range.

\subsection{Comparison between precipitation reconstruction and dryness/wetness indices}

Dryness/wetness indices derived from historical documents [37] are of great importance in studying past climate change, and they can be compared and crosschecked with tree-ringbased climate reconstructions. In this study, the coefficient of the correlation between annual precipitation series and dryness/wetness indices was -0.19 during 1771-1979 $(P<$ $0.01)$, and -0.28 during $1900-1979(P<0.05)$. Dryness/wetness indices provided evidences to demonstrate the reliability of our reconstruction to some extent. However, after the curves were smoothed by an 11-year moving average, it displayed obvious differences between the signals of the two series (Figure 7).

\subsection{Comparison with precipitation series of the Chifeng- Weichang region}

The Chifeng-Weichang region [20], the closest tree-ring research site to Kalaqin, is in the rim zone of the East Asian summer monsoon. The same species of trees were adopted to study climatic variation of the two regions, which may indicate the comparability of the precipitation series of the two sites. Two curves were significantly correlated with $r=$ $0.32(1768-2003, P<0.0001)$, and $r=0.39(P<0.0001)$ after applying an 11-year moving average. Synchronous variations of the two rainfall series were observed (Figure 8 ), and the dry years mostly happened during similar periods, such as 1800-1805, 1861-1866, 1903-1906, 1966-1968 and 1981-1986. In general, the amount of precipitation in Kalaqin was higher than that of Chifeng-Weichang, especially during the two intervals of 1815-1865 and 19251960. Figure 8 shows that the two series had relatively similar variation trends and amplitudes during 1866-1924 and 1986-1998. As stated above, both of the two curves may correspond to the variation of the East Asian summer monsoon. Thus, years with greater precipitation reflect years with comparatively strong monsoons, and vice versa. On the decadal scale, wet periods occurred with strong monsoons, and dry periods with weak monsoons.

The power spectrum analysis indicated that there were: 120 a, 80 a, 8 a, 2.42-2.02 a cycles in the reconstruction (Figure 9). The 80 a cycle was close to the 70 a periodicity [14] of the thermohaline circulation of the North Atlantic Ocean, and the quasi- 2 a periodicities were relatively similar to those of the Tropospheric biennial oscillation [38]. Together, this indicated that there were some teleconnections between the precipitation variations in Kalaqin and those in climate at a larger spatial scale.

\section{Conclusions}

(1) Based on standard dendroclimatological methods, tree-ring climate response was investigated in the Kalaqin

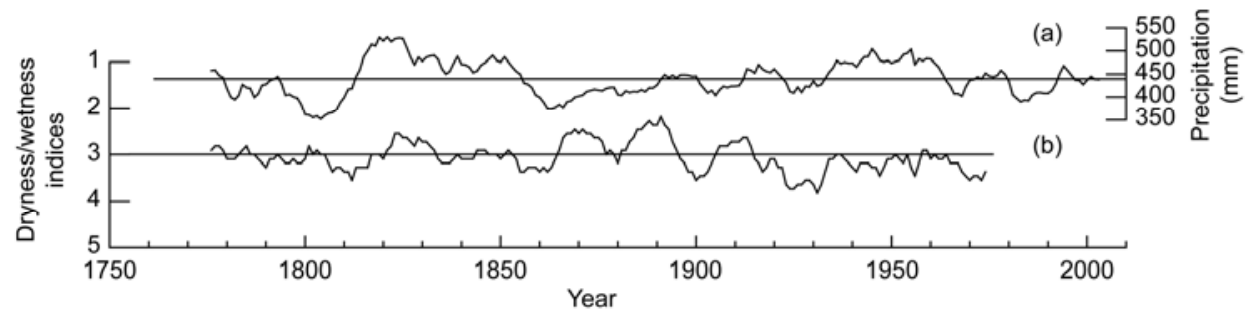

Figure 7 Comparison between the precipitation reconstruction of Kalaqin (a) and the dryness/wetness indices from Chifeng (b) during 1771-1979 (two curves were smoothed by an 11-year moving average).

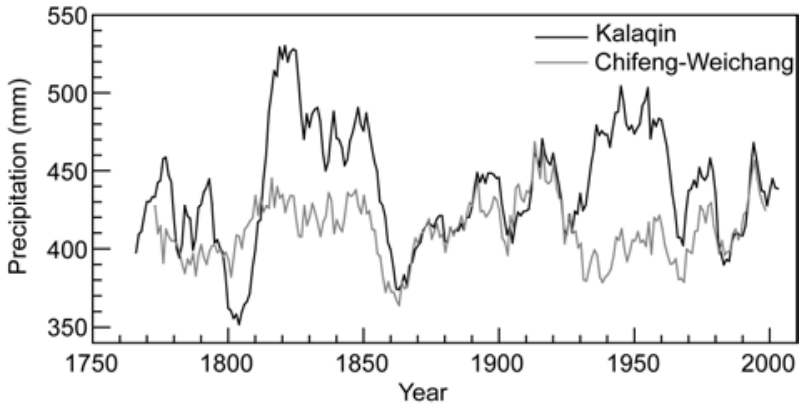

Figure $8 P_{87}$ comparison between Kalaqin and Chifeng-Weichang (11year moving average curves).

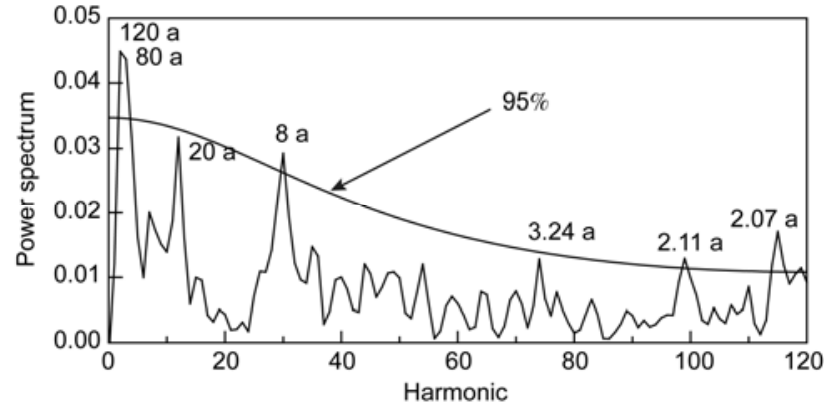

Figure 9 Power spectrum analysis of the $P_{87}$ for Kalaqin $(\operatorname{Lag}=120$ a). 
region, east Inner Mongolia. Total precipitation from the previous August to current July during 1771-2008 was reconstructed and verified using statistical techniques and other methods. Precipitation characteristics were analyzed through the reconstruction for Kalaqin.

(2) In the Kalaqin region, over the past 238 years, there were two long-term wet periods: 1813-1855, 1933-1963, and three severe dry periods: 1794-1812, 1856-1891 and 1980-1992.

(3) The severe drought event during 1784-1786 was confirmed to have happened in the Kalaqin region. The precipitation reconstruction compared well with that of the Chifeng-Weichang region nearby, and both of them reflected the strength of the East Asian summer monsoon. Years with greater precipitation reflected comparatively strong monsoons, and vice versa. On the decadal scale, wet periods occurred with strong monsoons, and dry periods with weak monsoons. Since 1960s, precipitation in this area has continuously increased, even though the precipitation is still in the normal range.

(4) The precipitation series of Kalaqin had 120 a, 80 a, 8 a, quasi-2 a periodicities, which indicated that there were some climatic teleconnections between Kalaqin and other regions.

The authors thank Bao Guang, Wang Yanchao, Lei Ying, Shen Baofa, Sun Junyan, Wang Yichen, Xie Li and Wang Ruiyuan for their help during the field work as well as the data analysis. This work was supported by the National Natural Science Foundation of China (40890051), the One-hundred Talents Program of the Chinese Academy of Sciences (KZCX2-YWQ1-01) and SKLLQG Foundation.

1 Briffa K R, Osborn T J, Schweingruber F H, et al. Low-frequency temperature variations from a northern tree-ring density network. $\mathrm{J}$ Geophys Res-A, 2001, 106: 2929-2941

2 Esper J, Cook E R, Schweingruber F H. Low frequency signals in long tree-ring chronologies for reconstructing past temperature variability. Science, 2002, 295: 2250-2253

3 D'Arrigo R, Jacoby G. A 1000-year record of winter precipitation from northwestern New Mexico, USA: A reconstruction from treerings and its relation to El Niño and the Southern Oscillation. The Holocene, 1991, 1: 95-101

4 Pederson N, Jacoby G C, D'Arrigo R D, et al. Hydrometeorological reconstructions for Northeastern Mongolia derived from tree rings: AD 1651-1995. J Clim, 2001, 14: 872-881

5 Cook B I, Miller R L, Seager R. Amplification of the North American "Dust Bowl" drought through human-induced land degradation. Proc Natl Acad Sci USA, 2009, 106: 4997-5001

6 Liu Y, An Z S, Linderholm H W, et al. Annual temperatures during the last 2485 years in the mid-eastern Tibetan Plateau inferred from tree rings. Sci China Ser D-Earth Sci, 2009, 52: 348-359

7 Yang B, Kang X C, Brauning A, et al. A 622-year regional temperature history of southeast Tibet derived from tree rings. Holocene, 2010, 20: 181-190

8 Gou X H, Chen F H, Yang M X, et al. Asymmetric variability between maximum and minimum temperatures in North-eastern Tibetan Plateau: Evidence from tree rings. Sci China Ser D-Earth Sci, 2008, 51: 41-55

9 Liang E Y, Shao X M, Qin N S. Tree-ring based summer temperature reconstruction for the source region of the Yangtze River on the
Tibetan Plateau. Glob Planet Change, 2008, 61: 313-320

10 Liu X H, Qin D H, Shao X M, et al. Temperature variations recovered form tree-rings in the middle Qilian Mountain over the last millennium. Sci China Ser D-Earth Sci, 2005, 48: 521-529

11 Liu Y, An Z S, Ma H Z, et al. Precipitation variation in the northeastern Tibetan Plateau recorded by the tree rings since $850 \mathrm{AD}$ and its relevance to the Northern Hemisphere temperature. Sci China Ser D-Earth Sci, 2006, 49: 408-420

12 Shao X M, Huang L, Liu H B, et al. Reconstruction of precipitation variation from tree rings in recent 1000 years in Delingha, Qinghai. Sci China Ser D-Earth Sci, 2005, 48: 939-949

13 Zhang Q B, Cheng G D, Yao T D, et al. A 2326-year tree-ring record of climate variability on the northeastern Qinghai-Tibetan Plateau. Geophys Res Lett, 2003, 30: 1739-1742

14 Liu Y, Sun J Y, Song H M, et al. Tree-ring hydrologic reconstructions for the Heihe River watershed, western China since AD1430. Water Res, 2010, 44: 2781-2792

15 Gou X H, Deng Y, Chen F H, et al. Tree ring based streamflow reconstruction for the Upper Yellow River over the past 1234 years. Chinese Sci Bull, 2010, 55: 4179-4186

16 Xu Y, Qian W H. Research on East Asian Summer Monsoon: A Review. Acta Geogr Sin, 2003, 58: 138-146

17 Liu Y, Tian H, Song H M, et al. Tree ring based reconstruction of the May-June mean temperature since A.D.1884 in Weichang, Hebei Province, China (in Chinese). Quat Sci, 2009, 29: 896-904

18 Wang L L, Shao X M, Huang L, et al. Tree-ring characteristics of Larix Gmelinii and Pinus Sylvestris Var. Mongolia and their response to climate in Mohe, China (in Chinese). Acta Phytoecol Sin, 2005, 29: 380-385

19 Liu Y, Bao G, Song H M, et al. Precipitation reconstruction from Hailar pine tree rings in the Hailar region, Inner Mongolia, China back to 1865 AD. Palaeogeogr Palaeoclimatol Palaeoecol, 2009, 282: 81-87

20 Liu Y, Tian H, Song H Y, et al. Tree ring precipitation reconstruction in the Chifeng-Weichang region, and East Asian summer monsoon variation since A. D. 1777. J Geophus Res, 2010, 115: D06106, doi: 10. 1029/2009JD012330

21 Liu Y, Sun J Y, Yang Y K, et al. Tree-ring precipitation records from Inner Mongolia, China, and the East Asian summer monsoon front variation since 1627 AD. Tree-ring Res, 2007, 63: 3-14

22 Liu Y, Cai Q F, Shi J F, et al. Seasonal precipitation in the southcentral Helan Mountain region, China, reconstructed from tree-ring width for the past 224 years. Can J For Res, 2005, 35: 2403-2412

23 Liu Y, Shishov V, Shi J F, et al. The forecast of seasonal precipitation trend at north Helan Mountain and Baiyinaobao regions, Inner Mongolia for next 20 years. Chinese Sci Bull, 2004, 49: 410-415

24 Wang W H. Climate of Inner Mongolia (in Chinese). Beijing: China Meteorological Press, 1990. 1-273

25 Stokes M A, Smiley T L. An Introduction to Tree-ring Dating. Chicago: University of Chicago Press, 1968. 1-73

26 Holmes R L. Computer-assisted quality control in tree-ring dating and measurement. Tree-Ring Bull, 1983, 43: 69-78

27 Cook E R, Kairiukstis L A. Methods of Dendrochronology. The Netherlands, Dordrecht: Kluwer Academic Publishers, 1990. 1-200

28 Wigley T M L, Briffa K R, Jones P D. On the average value of correlated time series with applications in dendroclimatology and hydrometeorology. J Clim Appl Meteorol, 1984, 23: 201-213

29 Kohler M A. On the use of double-mass analysis for testing the consistency of meteorological records and for making required adjustments. Bull Amer Meteorol Soc, 1949, 30: 188-189

30 Mann H B. Non-parametric test against trend. Econometrika, 1945, 13: 2452-2591

31 Efron B. Bootstrap methods: Another look at the jackknife. Ann Stat, 1979, 7: 1-26

32 Shao J, Tu D. The Jackknife and Bootstrap. Springer Series in Statistics. New York: Springer, 1995. 1-516

33 Zhang D E. Variation of dry-wet climate and severe drought events as revealed in the climate records of China over the past 1000 years 
(in Chinese). Sci Tech Rev, 2004, 8: 47-50

34 Wei S S. Drought events in past period of China. Knowl Power, 2009, 4: $16-18$

35 Ding Y H, Wang Z Y, Sun Y. Inter-decadal variation of the summer precipitation in East China and its association with decreasing Asian summer monsoon. Part I: Observed evidences. Int J Climatol, 2007, 28: 1139-1161

36 Ding $\mathrm{Y} \mathrm{H}$, Sun $\mathrm{Y}$, Wang $\mathrm{Z} \mathrm{Y}$, et al. Inter-decadal variation of the summer precipitation in East China and its association with decreasing Asian summer monsoon. Part II: Possible causes. Int J Climatol, 2009, 29: 1926-1944

37 Academy of Meteorological Science. Yearly Charts of Dryness/ Wetness in China for the Last 500-year Period (in Chinese). Beijing: China Maps Press, 1981. 1-332

38 Meehl G A, Arblaster J M. The tropospheric biennial oscillation and Indian monsoon rainfall. Geophys Res Lett, 2001, 28: 1731-1734

Open Access This article is distributed under the terms of the Creative Commons Attribution License which permits any use, distribution, and reproduction in any medium, provided the original author(s) and source are credited. 